\title{
The Position of the Testis during the Fetal Period. An Additional Parameter to Estimate Fetal Weight
}

\author{
Luciano A. Favorito, Waldemar S. Costa, Francisco J. B. Sampaio \\ Urogenital Research Unit, State University of Rio de Janeiro, UERJ, Rio de Janeiro, RJ, Brazil
}

\begin{abstract}
Purpose: To establish a correlation between testicular position and fetal weight, in order to provide an additional prenatal parameter for fetal weight estimation.

Materials and Methods: We studied 288 testes from 144 human fetuses. The fetuses were assessed as regards weight, total length, crown-rump length and foot length. Fetal age was calculated according to the foot length criteria. The position of the testis was classified as abdominal, inguinal or scrotal.

Results: One hundred and ninety seven testes (68.4\%) were abdominal, $43(14.9 \%)$ were inguinal and $48(16.6 \%)$ were scrotal. In the fetuses weighing up to 500 grams, 147 testes $(93.5 \%)$ were abdominal and 5 testes $(6.5 \%)$ were inguinal. In fetuses weighing between 501 and 1000 grams, 54 testes $(68.6 \%)$ were abdominal, 28 testes $(32.5 \%)$ were inguinal and 4 testes $(4.6 \%)$ were scrotal. In fetuses weighing between 1001 and 1500 grams, 4 testes $(13.3 \%)$ were abdominal, 3 $(10 \%)$ were inguinal and $23(76.6 \%)$ were scrotal. All fetuses weighing more than 1500 grams presented the testes with a migration to the scrotum (10 fetuses - 20 testes).

Conclusions: To our knowledge, this is the first study correlating the testicular position to the fetal weight during testicular migration in human fetuses. Identification of the testes during the prenatal period could be a useful alternative parameter for estimating fetal weight.
\end{abstract}

Key words: testis; migration; fetal development; fetal weight; prenatal ultrasound; prematurity

Int Braz J Urol. 2010; 36: 609-13

\section{INTRODUCTION}

The human testis develops in the abdomen and migrates to the scrotum during the second trimester of gestation, completing the process near the 30th week after conception (1). Testicular migration is divided into two phases; the first phase corresponds to the migration of the testis from the abdomen to the internal inguinal ring, whereas the second phase corresponds to the passage of the testis through the inguinal canal, until its final destination in the scrotum (2).
The main theories that attempt to explain the testicular migration process are the increase of intraabdominal pressure (3), the development of testicular gubernaculum, the development of the processus vaginalis, inguinal canal and spermatic vessels (2) as well as the production of gonadotrophins by the placenta that stimulates the production of testicular androgens (4).

Certain parameters can be used to estimate the fetal weight by ultrasound, as abdominal circumference, femur length, and size of the fetal head (5). Although they are not precise, these parameters are 
still used in routine practice, especially to detect low and very low birth weights (less than $1500 \mathrm{~g}$ ). Low birth weight infants can present various complications after conception, thereby influencing the growth and health of the individual in the future (6).

The aim of this study was to establish a correlation between the position of the testis and fetal weight, in order to use the testicular position as an additional prenatal ultrasonic parameter for fetal weight estimation.

\section{MATERIALS AND METHODS}

We studied 288 testes from 144 fresh human male fetuses that died of causes unrelated to the urogenital tract. The fetuses were macroscopically well preserved and no external evidence of congenital malformation was detected. After death, the fetuses were maintained refrigerated $\left(4^{\circ} \mathrm{C}\right)$ for a period of 24 to 72 hours. Then, the fetuses were analyzed based on their morphometric parameters (weight, total length, crown-rump length and foot length). All measurements were performed by the same investigator. The gestational age of the fetuses was determined in weeks post conception, according to the foot length criteria, which currently is the most acceptable method to estimate the fetal age (7-10).

The abdominal and pelvic cavities were opened, and the position of the testes was determined. The testis was regarded as abdominal when it was proximal to the internal inguinal ring, canalicular or inguinal when it was between the internal and external inguinal ring, and descended or scrotal when it was inferior to the external ring (1).

The present study was approved by the State University of Rio de Janeiro Bioethics Committee and all parents signed an informed consent form

\section{RESULTS}

Of the 288 testes studied, 197 (68.4\%) were abdominal, 43 (14.9\%) were inguinal and 48 (16.6\%) were scrotal.

The relationships between fetal weight and the position of the testis are shown in Figure-1.
In fetuses weighing up to 500 grams ( 76 fetus - 152 testes), 147 testes (93.5\%) were abdominal and $5(6.5 \%)$ were inguinal.

In fetuses weighing between 501 and 1000 grams (43 fetuses - 86 testes), 54 testes (68.6\%) were abdominal, $28(32.5 \%)$ were inguinal and only $4(4.6 \%)$ had completed their migration (scrotal). All 4 testes that had migrated to the scrotum were in fetuses weighing more than 970 grams. No testis in the scrotum was found in any fetuses weighing less than 970 grams.

In fetuses weighing between 1001 and 1500 grams (15 fetuses - 30 testes), 4 testes (13.3\%) were abdominal, 3 (10\%) were inguinal and 23 (76.6\%) were scrotal. All fetuses weighing more than 1500 grams presented the testes in the scrotum (10 fetuses - 20 testes).

\section{Comments}

Various parameters have been proposed to determine the gestational age of human fetuses, such as crown-rump length, femur length, fetal weight, biparietal diameter, orbital and frontal bone diameter and foot length (7-9.11-13). After the 12th gestational week, in the event that the last menstruation date was not known, the foot length measurement is considered by ultrasonographists, morphologists, obstetricians and perinatologists as being the best parameter to determine the gestational age (7-9).

Studies that correlate the position of the testes and the gestational age in human fetuses are scarce $(1,14)$. Sampaio and Favorito (1) have previously reported the chronology of testicular migration in human fetuses in a sample of 73 fetuses (146 testes). However, only limited importance has been given to the correlation between the fetal weight and the position of the testes during the fetal period. To our knowledge, there are no reported studies correlating the fetal weight to the position of the testes analyzing a significant number of human fetuses.

The estimate of fetal weight during ultrasound screening is of practical importance, especially in pregnant women who are clinically suspected of delivering low and very low birth weight infants (less than 1500 grams) (15). The identification of possible 


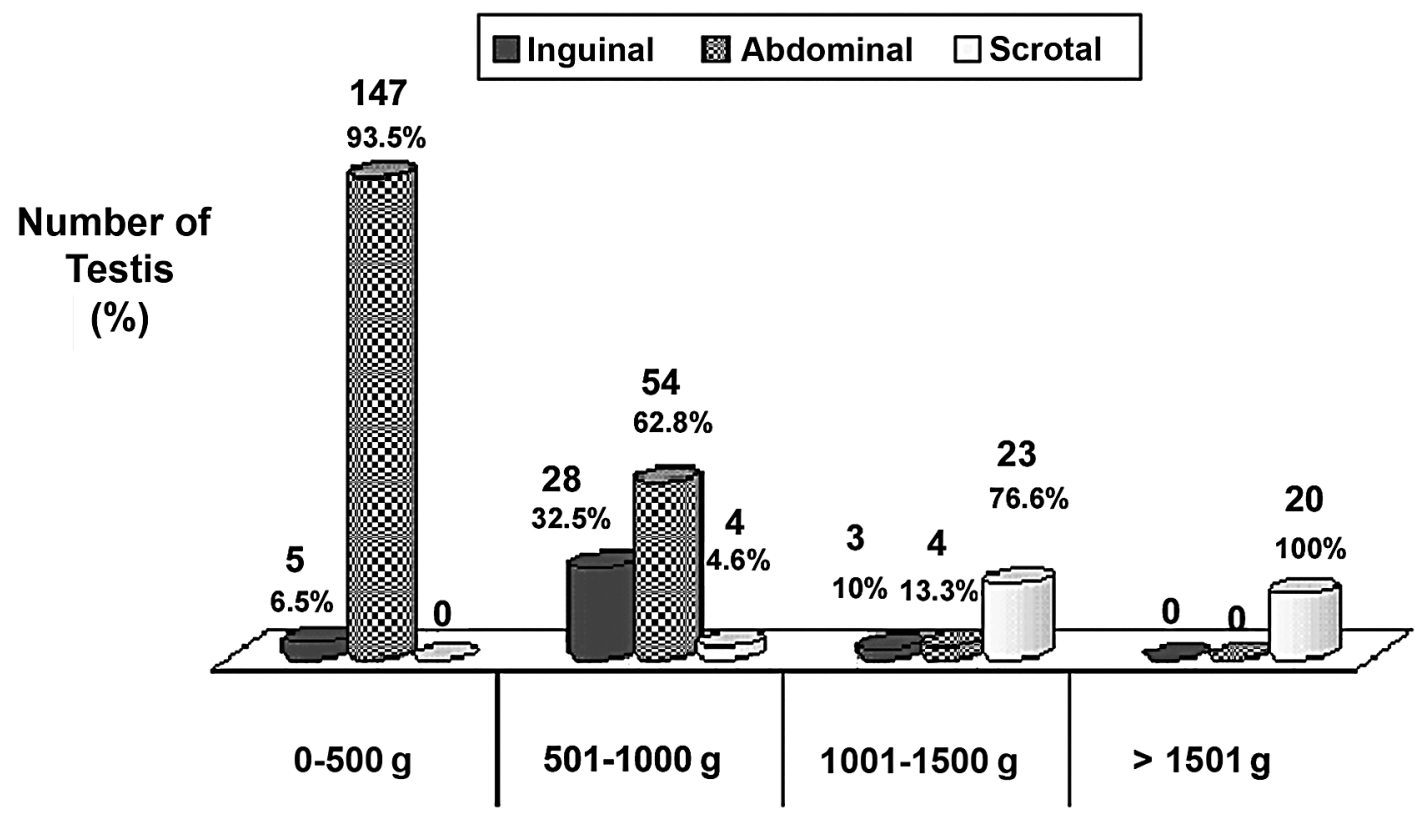

Fetal Weight

Figure 1 -Relationships between the position of the testes and the fetal weight during the fetal period in 288 testes studied.

low birth weight infants before their conception would permit early stage monitoring. Low birth weight infants can present major complications during and after delivery. In fact, it has previously been demonstrated that pregnant women who presented this possibility at prenatal examination and strictly monitored had a lower rate of fetal complications (16).

The most frequently used parameters in obstetric ultrasound to calculate fetal weight is not considered highly accurate (17). Recently, the use of the formula (fetal weight $=5381.193+150.324 \mathrm{x}$ head circumference $+2.069 \mathrm{x}$ femur length $+0.0232 \mathrm{x}$ abdominal circumference $\mathrm{x} 3-6235.478 \mathrm{x}$ logarithm of the head circumference) was developed. This formula incorporates the most frequently used fetal biometric parameters for ultrasound measurements that have proved to be easier and more accurate in estimating the weight of fetuses weighing less than 1600 grams (18).
The visualization of the fetal testis is feasible by intrauterine ultrasound during gestation, also making possible the measurement of testicular diameters and their position in the abdomen, pelvis or scrotum (19-21).

In the present study, we found that in fetuses weighing less than 970 grams no testes had completed the migration to the scrotal position. Thus, when the testis cannot be visualized in the scrotum, this should indicate that the fetus would probably weigh less than 1000 grams.

When analyzing fetuses weighing between 1001 and 1500 grams, only $13 \%$ of the testes were positioned in the abdomen and more than $76 \%$ of the testes had already completed their migration to the scrotum. All fetuses weighing more than 1500 grams had their testes positioned in the scrotum. We did not find any fetus weighing less than 970 grams that had completed testicular migration. 
If the testes are still in the abdomen during a prenatal ultrasonic assessment, this fetus has a $70 \%$ of chance of weighing less than 1000 grams and a $13 \%$ chance of weighing between 1000 and 1500 grams. If the testes are in the scrotum, the fetus has an approximately $5 \%$ chance of weighing less than 1000 grams and a $75 \%$ chance of weighing between 1000 and 1500 grams. The evaluation of testicular position ultrasound evaluation would be a viable and useful alternative for estimating the fetal weight.

\section{CONFLICT OF INTEREST}

None declared.

\section{ACKNOWLEDGEMENTS}

This work was supported by grants from the National Council of Scientific and Technological Development $(\mathrm{CNPq})$ and the Rio de Janeiro Foundation for Research Support (FAPERJ)

Carla B M. Gallo, B.Sc., M.S. prepared the figure and edited the manuscript.

\section{REFERENCES}

1. Sampaio FJ, Favorito LA: Analysis of testicular migration during the fetal period in humans. J Urol. 1998; 159: $540-2$.

2. Heyns CF, Hutson JM: Historical review of theories on testicular descent. J Urol. 1995; 153: 754-67.

3. Frey HL, Rajfer J: Role of the gubernaculum and intraabdominal pressure in the process of testicular descent. J Urol. 1984; 131: 574-9.

4. Husmann DA, Levy JB: Current concepts in the pathophysiology of testicular undescent. Urology. 1995; 46: 267-76.

5. Mladenovic-Segedi L, Segedi D: Accuracy of ultrasonic fetal weight estimation using head and abdominal circumference and femur length. Med Pregl. 2005; 58: 548-52.

6. Hack M, Schluchter M, Cartar L, Rahman M, Cuttler L, Borawski E: Growth of very low birth weight infants to age 20 years. Pediatrics. 2003; 112: e30-8.

7. Hern WM: Correlation of fetal age and measurements between 10 and 26 weeks of gestation. Obstet Gynecol. 1984; 63: 26-32.
8. Mercer BM, Sklar S, Shariatmadar A, Gillieson, MS, D'Alton MK: Fetal foot length as a predictor of gestacional age. Am J Obst Gynecol. 1987; 156: 350-6.

9. Platt LD, Medearis AL, DeVore GR, Horenstein JM, Carlson DE, Brar HS: Fetal foot length: relationship to menstrual age and fetal measurements in the second trimester. Obstet Gynecol. 1988; 71: 526-31.

10. Favorito LA, Albuquerque LF, Sampaio FJ, Costa WS: Disposition of the striated sphincter and its relation to the prostate in human fetuses. Int Braz J Urol. 2007; 33: 414-20.

11. Mantoni M, Pedersen JF: Fetal growth delay in threatened abortion: an ultrasound study. Br J Obstet Gynaecol. 1982; 89: 525-7.

12. Warda AH, Deter RL, Rossavik IK, Carpenter RJ, Hadlock FP: Fetal femur length: a critical reevaluation of the relationship to menstrual age. Obstet Gynecol. 1985; 66: 69-75.

13. Kopta MM, May RR, Crane JP: A comparison of the reliability of the estimated date of confinement predicted by crown-rump length and biparietal diameter. Am J Obstet Gynecol. 1983; 145: 562-5.

14. Achiron R, Pinhas-Hamiel O, Zalel Y, Rotstein Z, Lipitz S: Development of fetal male gender: prenatal sonographic measurement of the scrotum and evaluation of testicular descent. Ultrasound Obstet Gynecol. 1998; 11: 242-5.

15. Cicognani A, Alessandroni R, Pasini A, Pirazzoli P, Cassio A, Barbieri E, et al.: Low birth weight for gestational age and subsequent male gonadal function. J Pediatr. 2002; 141: 376-9.

16. Lindqvist PG, Molin J: Does antenatal identification of small-for-gestational age fetuses significantly improve their outcome? Ultrasound Obstet Gynecol. 2005; 25: 258-64.

17. Ben-Haroush A, Yogev Y, Hod M, Bar J: Predictive value of a single early fetal weight estimate in normal pregnancies. Eur J Obstet Gynecol Reprod Biol. 2007; 130: 187-92.

18. Schild RL, Fell K, Fimmers R, Gembruch U, Hansmann M: A new formula for calculating weight in the fetus of $<$ or $=1600 \mathrm{~g}$. Ultrasound Obstet Gynecol. 2004; 24: 775-80.

19. Rotondi M, Valenzano F, Bilancioni E, Spano G, Rotondi M, Giorlandino C: Prenatal measurement of testicular diameter by ultrasound: development of fetal male gender and evaluation of testicular descent. Prenat Diagn. 2001; 21: 112-5.

20. Pinette MG, Wax JR, Blackstone J, Cartin A: Normal growth and development of fetal external genitalia 
demonstrated by sonography. J Clin Ultrasound. 2003; 31: 465-72.

21. Mazza V, Di Monte I, Pati M, Contu G, Ottolenghi C, Forabosco A, Volpe A. 2004. Sonographic biometrical range of external genitalia differentiation in the first trimester of pregnancy: analysis of 2593 cases. Prenat Diagn 24: 677-684.

\section{Correspondence address:}

Dr. Luciano Alves Favorito

Urogenital Research Unit - UERJ

Av. 28 de Setembro, 87, Fundos - FCM - Térreo

Rio de Janeiro, RJ, 20551-030, Brazil

Fax: + 5521 2587-6121

E-mail: favorito@yahoo.com.br 